\title{
Development Status of the NSTAR Ion Propulsion System Power Processor
}

John A. Hamley, Luis R. Pinero, Vincent K. Rawlin, and John R. Miller Lewis Research Center

Cleveland, Ohio

Kevin C. Cartier

Analex Corporation

Brook Park, Ohio

Glen E. Bowers

Gilcrest Electric

Elyria, Ohio

Prepared for the

31st Joint Propulsion Conference and Exhibition cosponsored by AIAA, ASME, SAE, and ASEE San Diego, California, July 10-12, 1995
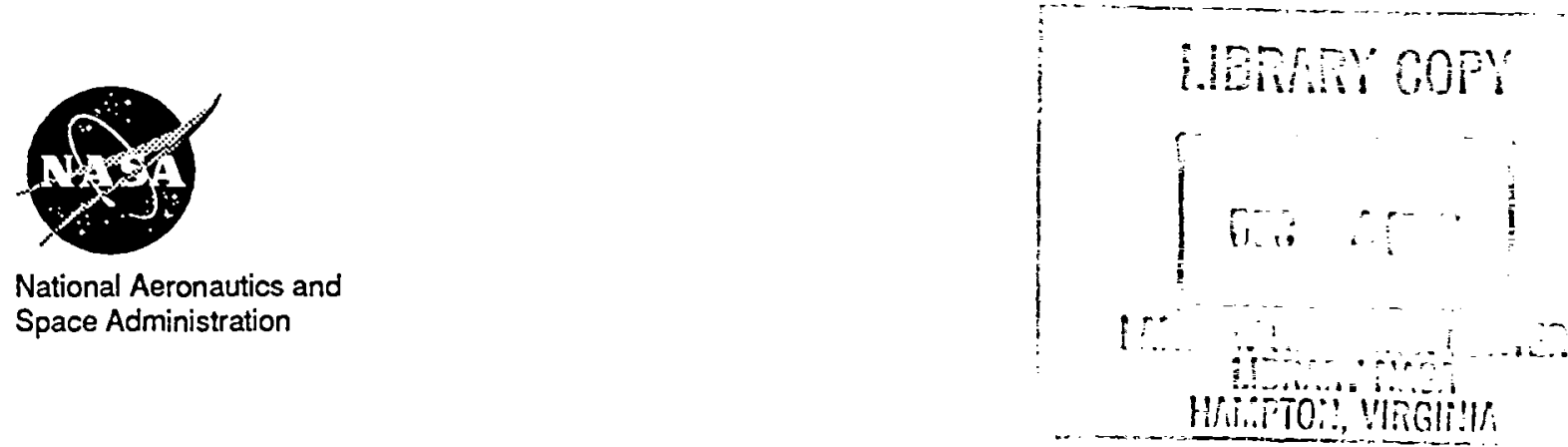



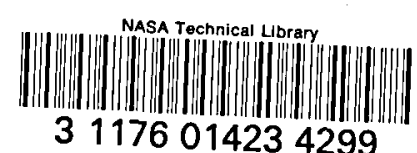

\title{
DEVELOPMENT STATUS OF THE NSTAR ION PROPULSION SYSTEM POWER PROCESSOR
}

\author{
John A. Hamley*, Luis R. Pinero*, Vincent K. Rawlint, John R. Miller** \\ NASA Lewis Research Center \\ Cleveland, Ohio 44135 \\ Kevin C. Cartiert† \\ ANALEX Corporation \\ Cleveland, Ohio 44142 \\ and \\ Glen E. Bowers*** \\ Gilcrest Electric \\ Elyria, Ohio 44035
}

\begin{abstract}
A $0.5-2.3 \mathrm{~kW}$ xenon ion propulsion system is presently being developed under the NASA Solar Electric Propulsion Technology Application Readiness (NSTAR) program. This propulsion system includes a $30 \mathrm{~cm}$ diameter xenon ion thruster, a Digital Control Interface Unit, a xenon feed system, and a power processing unit (PPU). The PPU consists of the power supply assemblies which operate the thruster neutralizer, main discharge chamber, and ion optics. Also included are recycle logic and a digital microcontroller. The neutralizer and discharge power supplies employ a dual use configuration which combines the functions of two power supplies into one, significantly simplifying the PPU. Further simplification was realized by implementing a single thruster control loop which regulates the beam current via the discharge current. Continuous throttling is possible over a $0.5-2.3 \mathrm{~kW}$ output power range. All three power supplies have been fabricated and tested with resistive loads, and have been combined into a single breadboard unit with the recycle logic and microcontroller. All line and load regulation test results show the power supplies to be within the NSTAR flight PPU specification. The efficiency of the beam power supply, which processes $80 \%$ of the power in the PPU was 0.92 at the full specified power output of $1.98 \mathrm{~kW}$. The overall efficiency of the PPU, calculated as the combined efficiencies of the power supplies and controller, at $2.3 \mathrm{~kW}$ delivered to resistive loads was 0.90 . The component mass was $6.16 \mathrm{~kg}$. Integration testing of the neutralizer and discharge power supplies with a functional model thruster revealed no issues with discharge ignition or steady state operation.
\end{abstract}

\section{INTRODUCTION}

High specific impulse ion propulsion systems (IPSs) have long been targeted as candidates for primary propulsion systems for both planetary and Earth-space spacecraft, and as auxiliary propulsion systems for geosynchronous communications spacecraft. 12 Several IPSs have reached an advanced state of development in the U.S. and abroad. ${ }^{3-}$ 11 Major issues with IPSs are the system cost and complexity, especially in the power processing unit (PPU). In some cases, the PPUs have contained over 4000 discrete parts and 12 power supplies to operate the thruster. 4

The system complexity was due to the mercury propellant utilized in the thruster. The transition to inert gas propellants significantly reduced PPU complexity by eliminating the power supplies used to vaporize the mercury and regulate its flow rate. During this transition period, several other PPU simplification techniques were identified. 13-15 These simplifications centered around less stringent power regulation requirements, which reduced parts count and cost, but were not adopted into a flight type PPU design.

The NASA Solar Electric Propulsion Technology Application Readiness (NSTAR) program is currently developing a high performance, simplified IPS. This propulsion system, which is throttleable from 0.5 to $2.3 \mathrm{~kW}$ output power to the thruster, targets primary propulsion applications for planetary and Earth-space missions. 1,2 The PPU requirements, which dictate a mass of less than $12 \mathrm{~kg}$ with an efficiency of 0.9 or greater at $2.3 \mathrm{~kW}$ output, forced a departure from state of the art PPU design. Several innovations including dual use topologies, simplified thruster control, and the use of ferrite magnetic materials were necessary to meet these requirements.

To reduce the level of complexity and parts count in the PPU, the design employed a "dual use" concept for the

\footnotetext{
* Electrical Engineer, On-Board Propulsion Branch, 21000 Brookpark Rd., MS SPT-D1

† Electrical Engineer, On-Board Propulsion Branch, 21000 Brookpark Rd., MS SPT-D1, Member AIAA

** Electronics Technician, Energy and Spacecraft Branch, 21000 Brookpark Rd., MS 301-1

i† Software Engineer, Flight Projects Branch, Engineering Department, 3001 Aerospace Parkway

*** Electronic Systems Mechanic, 570 Temes Ave
} 
discharge and neutralizer power supplies. This dual use topology derives power for the cathode heater and anode from the same power transformer which allows the construction of a single inverter each for the neurralizer and discharge power supplies. 16 The power for the screen and accelerator grids was also to be derived from a single transformer; however, this was found to be impractical.

Further simplifications were realized in the PPU with the application of a single closed loop, implemented in the microcontroller, for thruster control. This loop regulates the beam current, and thus the thrust produced, by varying the discharge current.

To minimize mass and optimize efficiency, the switching frequency of the power supplies which drive the thruster was set at $50 \mathrm{kHz}$. This frequency selection represents a compromise between low mass and high efficiency, and also allows the power transformers to be designed and fabricated with ferrite (ceramic) cores. If packaging of ferrite components for spaceflight becomes an issue, this frequency is still within the usable range of metallic core types which have an extensive heritage in flight designs. A full description of the rationale for the PPU design and control philosophy was previously published. 14

Recently, design changes have been implemented to accommodate the addition of a Digital Control Interface Unit (DCIU) to the NSTAR system, modification of the switching scheme used for output selection in the discharge and neutralizer power supplies, elimination of the MIL-STD-1553 interface on the PPU, and the addition of a dedicated accelerator grid power supply.

A breadboard version of the PPU has been fabricated to validate the dual use concept, verify closed loop stability within the individual power supplies and with the thruster, and to demonstrate an overall efficiency of greater than 0.9 . The neutralizer, discharge, and beam power supplies have been fabricated and have demonstrated full power operation into resistive loads. The neutralizer and discharge power supplies have been integrated with a functional model thruster, (FMT) and have demonstrated reliable discharge ignition and steady state operation over the full range of conditions expected over the NSTAR throttling range. This paper summarizes the status of the design and presents the results of resistive load and thruster integration tests to date.

\section{SYSTEM INTERFACES}

A block diagram of the PPU and its interfaces with the NSTAR system is shown in Figure 1. A departure from the previously reported design is the addition of the DCIU. 17 Mission requirements for deep space planetary and some Earth-space missions result in the need for more than one thruster to operate at any given time, resulting in the need for N PPUs, where $N$ is the maximum number of thrusters that will be operated at any one time.

The DCIU acts as a centralized command and data interface, sets the appropriate pressure in the xenon flow system (XFS) plena, opens the propellant valves to the selected thrusters, and relays thruster commands from the spacecraft to the appropriate PPU.
The NSTAR XFS supplies xenon to all thrusters through a two plenum system. Latch valves are used to open each of the three propellant lines connected to a thruster. The flow rate in any of the propellant lines is determined by the pressure in the plenum connected to that line, and the size of the flow resistor in the line. In this configuration, the flow rate to all of the thrusters is fixed by the plenum pressure, and no provisions for closed loop control of flow rate based on thruster parameters is implemented. The flow rate is chosen based on the selected thruster operating power. The DCIU has provisions to store a preset table of 15 flow rates corresponding to 15 thruster power levels. These flow rates are initialized prior to launch and can be modified in the course of the mission by ground command. The addition of the DCIU caused some changes in the PPU baseline design, and these are discussed in the following sections.

\section{PPU DESIGN}

A block diagram of the original NSTAR PPU design appears in Figure 2. The PPU contained the neutralizer, discharge, and beam/accelerator power supplies to operate the thruster, a housekeeping power supply, and a microcontroller with a command and telemetry interface. Power was drawn from two power busses, a $28 \mathrm{~V}$ regulated low power bus for housekeeping and controls, and a 80-120 VDC high power bus for the thruster power supplies. The discharge and neutralizer power supplies are shown with the original "dual use" output switching configuration and are push-pull, or parallel, converters. The beam/accelerator supply was a zero voltage switched full bridge converter with multiple low voltage secondaries, each with a bridge rectifier and output filter. This configuration was chosen to allow the use of low voltage rectifiers and filter capacitors in the output stages to reduce the mass and volume of the filter capacitors.

A full-bridge topology was chosen for the beam power supply because of the high power output and the adaptability of this topology to a zero voltage switched configuration to minimize switching losses. Four of the output filter capacitors were connected in series to develop the 1100 VDC output for the screen grid. One of the secondaries was to have provided a variable DC output which fed a linear series-pass regulator to provide power for the accelerator grid. This concept was abandoned for reasons which will be discussed in la later section. The output specifications for the power supplies which operate the thruster are summarized in Table 1.

A microcontroller is used to sequence the power supplies, digitize telemetry data, and provide a command/telemetry interface. The command/telemetry interface for the breadboard PPU is an RS-232 interface operating at 9600 baud. This design was described in detail elsewhere. ${ }^{14}$

A block diagram of the present NSTAR breadboard PPU is presented in Figure 3. The major modifications to the breadboard assembly include changes in the switching scheme used for output selection in the discharge and neutralizer power supplies and the addition of a dedicated accelerator grid power supply. 
Neutralizer and Discharge Power Supplies

Originally, a single relay was used to interrupt power to the heaters on the neutralizer and discharge cathodes. In this configuration, while power was applied to the cathode heater, some voltage appeared on the neutralizer keeper or discharge anode. In the absence of propellant flow this was not an issue, however, early power supply/thruster integration tests indicated that the discharges would light with anode potentials of less than $50 \mathrm{~V}$. To prevent an inadvertent ignition while heating the cathode, propellant flow to the cathode must be cut off during the heating process. Flow can then be initiated when the power supply is in the anode or keeper mode. Since the PPU does not have control of the propellant valves, the opening of any thruster latch valve would have to have been synchronized with the PPU connected to that thruster.

A software solution could have been implemented, but for simplicity, another relay was added in the output circuit of the power supplies as shown in Figure 3. With this configuration, voltage can only appear across the load being driven, the heater or the anode. Therefore, flow to the cathode can be initiated at any time during the heating process, and inadvertent ignition is impossible. A further benefit is realized in that a single inductor can be used to filter the output current of the power supply, as opposed to the two inductors previously used. The relays selected were space qualified vacuum relays which have a mass of 0.03 $\mathrm{kg}$. With the elimination of an output inductor and the addition of the second relay, the net mass of the neutralizer and the discharge power supplies was reduced from the original design.

In the event that the discharges do not ignite on the open circuit voltage of the power supplies, a pulse ignitor has been included in the power supply assemblies. This circuit utilizes the output filter inductor as a pulse transformer by adding a second winding to the inductor. This circuit was originally designed for the ignition of arcjets, and has also been used to ignite other hollow cathode discharges. 18,19

\section{Accelerator Power Supply}

The original "dual use" concept for the Beam/Accelerator power supply called for the use of a linear regulator which drew power from the main power transformer in the beam power supply. Resistive load tests of the beam/accelerator supply, which will be discussed in detail in a later section, showed that this was not a practical implementation. A more practical solution was found to be the addition of a dedicated, low power flyback converter to supply the voltage to the accelerator grid.

\section{Input Filters}

For the purposes of the breadboard effort, it was decided to not implement a MIL-STD-461 compliant input filter design. A single stage differential mode input filter was installed on the inputs of the three thruster power supplies. These filters were designed to provide $40 \mathrm{~dB}$ of attenuation at the input current fundamental ripple frequency of 100 $\mathrm{kHz}$.

\section{Controller}

The original concept of the PPU controller made provisions for three commands. These included thruster off, thruster on at power level $\mathrm{M}$, and condition cathodes. Further system development work has resulted in the addition of several more commands to the PPU to improve system flexibility. The first of these commands involves the throttling table stored in the PPU. This table contains 15 power levels which can be selected over the mission as power availability varies. A typical power table is listed in Table 2. This table is stored in the controller ROM and is written to RAM at system power up. A command is now available to adjust any parameter in the table to compensate for changes in the thruster or spacecraft power system during the course of a mission. This effectively implements a continuous throttling capability over the full $0.5-2.3 \mathrm{~kW}$ operating range of the thruster. The 15 throttling points, stored in ROM, provide backup in the event of an anomaly in the controller RAM.

To facilitate varying data requirements, the PPU telemetry is now obtained by a command which polls the telemetry buffer in the PPU. Upon receipt of this command, the latest data frame is transmitted to the DCIU. A maximum data rate of one frame per second is supported. Finally, a command set which allows the manual operation of each of the power supplies was added for flexibility in testing and system troubleshooting.

\section{PPU FABRICATION STATUS}

At the time of this writing, the neutralizer, discharge, and the beam/accelerator supply have been fabricated, and all power supplies, with the exception of the accelerator regulator have been successfully tested with resistive loads. The neutralizer and discharge power supplies have been integrated with a functional model thruster (FMT). All three power supplies have been integrated into a single breadboard assembly.

The microcontroller and housekeeping power supply are commercially available units and have been installed in the breadboard assembly along with the stand-alone recycle logic. All control and data acquisition software in the PPU microcontroller was written and tested with a PPU simulator, with the exception of the beam current regulation loop. This loop will be implemented following integration tests of the thruster under manual control. A full description of the control software is beyond the scope of this paper and will be published at a later date.

\section{TEST PROCEDURES}

\section{Resistive Loads}

The PPU breadboard was connected to a resistive load which was capable of simulating the thruster electrical loads over the $0.5-2.3 \mathrm{~kW}$ NSTAR throttling range. Each power supply was operated separately in order to characterize its line and load regulation, and efficiency. The microcontroller was powered during these tests, but did not control the power supplies. Control was implemented with a manual test box. Load regulation was tested by setting the input power supply voltage to $80 \mathrm{~V}$ and setting the output of the supply under test to a fixed setpoint, and sweeping the load resistance over the operating range of the power supply. Load regulation was defined as the maximum measured output minus the 
minimum measured output divided by the setpoint. This test was repeated with the input voltage increased by 10 VDC until the full input voltage range of $80-120$ VDC was tested.

Line regulation was tested by setting the input power supply voltage to $80 \mathrm{~V}$ and setting the output of the supply under test to a fixed setpoint, and sweeping the input voltage over the $80-120$ VDC operating range of the power supply. Line regulation was defined as the maximum measured output minus the minimum measured output divided by the setpoint.

Efficiencies of each of the power supplies were tested individually. Input and output voltages were measured using digital voltmeters (DVMs). Input and output currents were measured with shunt resistors. The voltage drops across the shunt resistors were also measured with DVMs. The estimated uncertainty of the efficiency measurements was $\pm 0.1 \%$. Housekeeping power, including power to the controller, was measured during these tests. Overall PPU efficiency was calculated using the sum of the output powers of the three power supplies, divided by the sum of the input power on the $80-120 \mathrm{~V}$ and $28 \mathrm{~V}$ bus. It should be noted here that the values given will not include the efficiency of the accelerator converter.

\section{Thruster Integration Tests}

Presently, only the neutralizer and discharge power supplies had been tested with the FMT. The FMT was installed in a vacuum facility with a laboratory xenon flow system. The power supplies were separately tested, to assess both the discharge ignition characteristics and steady state operation. The xenon flow rate was established at a typical operating point of the NSTAR system and power was applied to the cathode heater. After a five minute heating interval the power supply was switched off and the anode output was selected. The power supply was then turned back on. If the cathode discharge did not ignite, the pulse ignitor was energized. The process was done manually, to simulate a worst case condition where a long time interval elapsed between the removal of heater power and the application of power to the anode. During the "off" period the cathode insert would be cooling, possibly making ignition difficult. With the microcontroller, this process would be accomplished in milliseconds. After the ignition tests were completed, the volt-ampere characteristics of the discharges were measured, and the steady state operation of the converters was assessed over the full throttling range.

\section{RESULTS AND DISCUSSION}

Resistive Load Tests

The results of resistive load tests are presented for the anode outputs of the neutralizer and discharge power supplies, and the beam output of the beam/accelerator power supplies. The cathode heater outputs are not included because they are not used during steady state operation. As previously stated, the accelerator output was non-functional in the original configuration. A decision was made to replace it with a stand-alone power converter. This converter was not completed in time to include the results of any resistive load tests in this report.
The specifications of Table 1 list the output range of the neutralizer power supply as 8 - 32 VDC. With the output of the neutralizer power supply set at $1.95 \mathrm{~A}$, the load regulation was in within $\pm 0.2 \%$ of this setpoint between 6 and 30 VDC. The test data are presented in Figure 4.

The results of the neutralizer line regulation test are shown in Figure 5. The neutralizer load was set to $8 \Omega$ resulting in a $16 \mathrm{~V}$ output voltage at $1.95 \mathrm{~A}$ output current. The input voltage was swept over the full $80-120 \mathrm{~V}$ range, and the output current regulation was again better than $\pm 0.2 \%$

Discharge load regulation test results are shown in Figure 6. The operating range of the discharge power supply was between 4 and $12.5 \mathrm{ADC}$. The supply was tested at setpoints of $4,6,8,10$, and $12 \mathrm{~A}$, and the load regulation was found to be $\pm 1 \%$ over the operating range of the power supply.

The results of the line regulation test are shown in Figure 7. For this test, the discharge power supply output was set to 12.0 ADC into a $2.3 \Omega$ load. The total variation in output current was less than $\pm 0.1 \%$ over the $80-120$ VDC input voltage range.

The beam power supply was connected to a resistive load with the output set at $1100 \mathrm{~V}$. Load resistance was varied to draw a range of output current from 0.5 to $1.8 \mathrm{ADC}$. The results of this test are shown in Figure 8. The output voltage was found to vary from $1108-1084$ VDC, which is a load regulation of $2.3 \%$. This variation is within specification, but the error is larger than demonstrated by the other power supplies. This is due to the limitation in feedback voltage to values of less than $2.5 \mathrm{~V}$ in the telemetry/feedback circuits. The feedback voltage is provided by a 1:1000 voltage divider, and the $25 \mathrm{~V}$ of error represents a $25 \mathrm{mV}$ delta in the feedback circuit. The regulation of the supply would be greatly improved with an increase in gain in the voltage feedback loop.

During the course of the beam power supply testing, the diodes specified for the output rectifiers proved to be of insufficient peak reverse voltage rating for the high end of the $80-120$ VDC input voltage range, and will have to be replaced with higher voltage diodes for future tests. Therefore, at the time of publication, the line regulation tests were not completed.

The output of the accelerator section is nominally 150 $180 \mathrm{VDC}$ at less than $10 \mathrm{~W}$. The low output current $(<30$ $\mathrm{mA}$ ) results in the need for a large filter inductor to ensure continuous load current in the inductor. This condition is necessary to clamp the secondary winding to approximately zero volts during the PWM "off" intervals of the power MOSFETs in the power stage. If this condition does not exist, the secondary will be unclamped and will oscillate at the resonant frequency of the parasitic impedances of that winding. Due to mass considerations, the inductor was not designed for continuous conduction. It was hoped that the oscillations of the unclamped winding could be easily damped. Unfortunately, the oscillations were of a large amplitude and attempts to damp the oscillations resulted in excessive power losses. Further, the undamped oscillations were found to interfere with the 
operation of the linear regulator, and it was decided to replace the regulator with a dedicated power supply to provide power to the accelerator grid. This power supply is currently being fabricated.

\section{Efficiency}

Approximately eighty percent of the total power delivered to the thruster is provided by the beam power supply. Therefore, the efficiency of the PPU will largely be determined by the efficiency of the beam supply. The results of preliminary efficiency tests for the beam power converter are shown in Figure 9. The efficiency was 0.92 at full power (1100 V @ $1.8 \mathrm{~A})$ with an $80 \mathrm{VDC}$ input. At lower power levels the efficiency increased to 0.95 with an output current of 0.5 A @1100 VDC. Two additional points are plotted at the $0.5 \mathrm{~A}$ output with the voltage set at 850 and $650 \mathrm{~V}$. The efficiency at these low power outputs was slightly less than 0.93 . These numbers do not include housekeeping power, because the housekeeping power is included in the overall efficiency values presented in the next section. It must be noted here that replacement of the output diodes as previously discussed will decrease the efficiency of the beam supply by approximately 0.006 at full power.

The efficiency of the PPU, as constructed, at 15 points spanning the throttling range with 80 VDC input is shown in Figure 10. The neutralizer and discharge power supplies were operated in tandem, and efficiency data were taken. These data were combined with beam power supply efficiency data taken earlier and the measured housekeeping power to arrive at an overall efficiency number. The efficiency of the neutralizer and discharge power supply combination was between 0.85 and 0.88 over the throttling range of the PPU. At $2.4 \mathrm{~kW}$ delivered to the thruster, the efficiency of the PPU was measured at 0.90 . The efficiency ranged from 0.90 to 0.92 from 0.8 to $2.4 \mathrm{~kW}$ delivered to the thruster and dropped to 0.87 with $0.5 \mathrm{~kW}$ delivered. These data again do not include the efficiency of the accelerator converter or the additional losses that may be associated with the replacement of the output diodes in the beam power supply. These additional losses should not reduce the efficiency by more than $0.2 \%$ Due to the inadequacies of the output diodes in the beam power supply, the efficiency of the PPU could not be measured at 120 VDC input. However, the efficiency at this input voltage should be comparable to, or $1-2 \%$ lower than the 80 VDC input efficiency.

These data are also compared with other existing power processors in Figure 10. The efficiency of the NSTAR PPU compares favorably with previous efforts. At deep throttling conditions, the NSTAR PPU again compares favorably with other the other PPUs that were designed to operate at these low power levels. This is due to the low conduction losses in the PPU at derated output. The total component mass for the breadboard assembly is $6.18 \mathrm{~kg}$, for a component specific mass of $2.7 \mathrm{~kg} / \mathrm{kW}$.

\section{Thruster Integration Tests}

The neutralizer and discharge power supplies were integrated with the FMT to characterize discharge ignition and verify stable steady state operation. Protocols for cathode conditioning and startup were followed as described by Sarver-Verhey. 20 The results with both power supplies were identical, therefore, only the results from the discharge power supply will be presented.

The discharge power supply was connected to the FMT and 80 VDC was applied to the high power input. This resulted in an open circuit voltage of 35 VDC. Since the open circuit output voltage of the power supply will increase with increasing input voltage, this point was selected to represent a worst case condition for ignition due to the low anode voltage. Oscilloscope traces of a sample ignition are shown in Figure 11. The main flow rate was set at $18.6 \mathrm{sccm}$ and the cathode flow rate at $2.9 \mathrm{sccm}$. The power supply output was set at $7.5 \mathrm{~A}$ for the heater output and $7.5 \mathrm{~A}$ for the discharge output. After a five minute preheat of the cathode, the power supply was tumed off and the anode output was selected. The power supply was turned on again and the ignition of the discharge was instantaneous. The power supply output remained at full open circuit voltage due to saturation of the error integrator, and the discharge current was approximately $10 \mathrm{~A}$ for $50 \mathrm{~ms}$. The current then ramped down, and the $7.5 \mathrm{~A}$ setpoint was reached after $100 \mathrm{~ms}$ of operation. A large AC noise component is seen on the discharge voltage immediately after ignition. This phenomenon may be due to the constant voltage operation of the power supply during the period of integrator saturation. As the discharge current ramped down to the setpoint, the power supply was acting as a current source, and the voltage noise was reduced significantly.

The instantaneous ignition of the discharge on power supply open circuit voltage may be the result of the rapid slew rate of the output voltage of the power supply. This rapid $d V / d t$ is possible because of the absence of a capacitor in the output filter of the power supply. Capacitors are not included in the output filters of the neutralizer and discharge power supplies because of the potential for current oscillations in the loop between the output filter and the thruster plasma. Power supplies with output capacitors tend to develop current oscillations which can be caused by a load with an impedance that has a negative slope at high frequencies. Without the output capacitor, the current ripple is determined only by the size of the output inductor, and has a sawtooth waveshape. Some discharge voltage oscillations result, but are generally less than $5 \mathrm{~V}$ p-p. This ignition behavior was displayed at all NSTAR operating points, and prevented the testing of the pulse ignitor. An attempt was made to allow the cathode to cool for 15 seconds prior to application of the anode voltage, but the cathode ignited without the aid of the pulse ignitor.

Following the ignition tests, a volt-ampere characteristic of the discharge was measured without beam extraction. The results of this test are shown in Figure 12. The discharge voltage remained between 19 and $25 \mathrm{~V}$, and the operation of the power supply was stable at all of these points. With beam extraction, the volt-ampere characteristic will shift upwards, increasing the discharge voltage. However, the range of discharge voltages were well within the output capabilities of the discharge power supply. 


\section{CONCLUSIONS}

A breadboard power processing unit has been fabricated under the NASA Solar Electric Propulsion Technology Application Readiness program. The PPU breadboard consists of the neutralizer, discharge, and beam/accelerator power supplies, recycle logic, and a digital microcontroller. The power supplies employ a dual use topology which combines the functions of two power supplies into one, significantly simplifying the PPU. The dual use configuration of the neutralizer and discharge power supplies has been modified to simplify the interface with the XFS and reduce the mass of the power supplies. A $50 \mathrm{kHz}$ switching frequency was selected to optimize the trade between mass and efficiency, allow the application of ferrite (ceramic) magnetic cores, and to facilitate a retreat to the proven metal tape core technology in the event of difficulty in packaging the ceramic components for spaceflight.

Further PPU simplification was realized by implementing a single thruster control loop which regulates the beam current via the discharge current. This control loop will be implemented via software in the microcontroller. All other control loops in the individual power supplies are implemented with analog circuits. A stand-alone DCIU has been added to the NSTAR system to facilitate the operation of several thruster and PPUs simultaneously. The DCIU acts as a centralized command and telemetry interface and also controls the xenon feed system. Flexibility was added to the original fifteen point throttling scheme which allows modification of the throttling table stored in the PPU and DCIU memory via ground command. This modification now makes continuous throttling of the thruster possible.

The neutralizer, discharge and beam power supplies have been fabricated and tested into a resistive load, and have been combined into a single breadboard unit with the housekeeping power supply and microcontroller. The neutralizer and discharge power supplies provided line and load regulation of better than $\pm 1 \%$, but some deviation from specifications were noted in the output ripple. This deviation can be corrected simply with an increase in size of the output filter inductors. The beam power supply load regulation was better than $3 \%$, which was within specification, and some simple modifications were identified to improve the regulation performance. The linear regulator concept for the accelerator output proved inadequate and a dedicated power supply is being fabricated to supply power to the accelerator grid.

The overall efficiency of the PPU, calculated based on the efficiencies of the individual power supplies, with $2.3 \mathrm{~kW}$ delivered to the thruster was approximately 0.90 . The efficiency of the PPU compared favorably with previous efforts in ion thruster PPU development. The component mass of the PPU breadboard was $6.16 \mathrm{~kg}$, and the estimated packaged mass was $13.6 \mathrm{~kg}$. This estimation packaged mass was $1.6 \mathrm{~kg}$ over the targeted mass, but the estimation method was not rigorous, and a more detailed estimation process must be carried out to determine the validity of this number.
Integration tests with the neutralizer and discharge power supplies and a functional model thruster demonstrated reliable ignition of the discharges and stable steady state operation. Discharge ignition was instantaneous on the open circuit voltage of the power supplies, and the pulse ignition system was not needed.

\section{ACKNOWLEDGEMENTS}

The authors wish to thank Messrs. Stanley Krauthamer and David Rogers of the Power Electronics Group of the Jet Propulsion Laboratory and Drs. Thomas Stuart and David King of the University of Toledo for their invaluable assistance in this project. Messrs. Louis Ignaczak and Robert Frye of NASA LeRC are also thanked for their lessons learned from past and present ion power processing efforts.

\section{REFERENCES}

1. Kakuda, R., Sercel, J., and Lee, W., "Small Body Rendezvous Mission Using Solar Electric Ion Propulsion: Low Cost Mission Approach and Technology Requirements," IAA Paper L-0710. April, 1994.

2. Janson, S.W., "The On-Orbit Role of Electric Propulsion," AIAA Paper 93-2220, June, 1993.

3. Kerslake, W.R., and Ignaczak, L.R., "Development and Flight History of SERT II Spacecraft," AIAA Paper 923516, July, 1992.

4. Biess, J.J., "Electrical Prototype Power Processor for the $30 \mathrm{~cm}$ Mercury Electric Propulsion Engine," AIAA Paper 78-684, April, 1978.

5. Herron, B.G., Hyman, J.Jr., and Hopper, D.J., "Development of an 8-cm Engineering Model Thruster System," AIAA Paper 76-1058, November, 1976.

6. Fearn, D.G., Martin, A.R., and Smith, P., "Ion Propulsion Development in the UK," AIAA Paper 93-2603. June, 1993.

7. Shimada, S., Satoh, K., Gotoh, Y., Nishida, E., Takegahara, H., Nakamaru, K., Nagano, H., and Terada, K., "Ion Engine Development of ETS-VI," IEPC 91-145, October, 1991.

8. Bassner, H., Berg, H.P., and Kukies, R., "RITA Development and Fabrication for the Artemis Satellite," IEPC Paper 91-057, October, 1991.

9. Herron, B.G., and Hopper, D.J., “ $30-\mathrm{cm}$ Ion Thruster Power Processor," NASA CR 135401, April, 1978.

10. Cybulski, R., et al., "Results From SERT I Electric Rocket Test," NASA TN E-2760, 1964.

11. Beattie, J.R., Matossian, J.N., and Robson, R.R., "Status of Xenon Ion Propulsion Technology," AIAA Paper 87-1003, May, 1987.

12. Rawlin, V.K., "Reduced Power Processor Requirements for the 30-cm Diam Mercury Ion Thruster," Electric Propulsion and Its Application to Space Missions, R.C. Finke, ed., Progress in Astronautics and Aeronautics, Vol. 79, 1981.

13. Rawlin, V.K., "Extended Operating Range of the 30-cm Ion Thruster with Simplified Power Processor Requirements," NASA TM 81279, 1981.

14. Gruber, R.P., "Simplified Power Supplies for Ion Thrusters," NASA TM 81275, 1981. 
15. Gruber, R.P., "Simplification of Power Electronics for Ion Thruster Neutralizers," AIAA Paper 82-1880, also NASA TM 83004, 1982.

16. Rawlin, V.K., Pinero, L.R., and Hamley, J.A., "Simplified Power Processing for Inert Gas Ion Thrusters," AIAA Paper 93-2397, June, 1993.

17. Hamley, J.A., et al., "A $2.5 \mathrm{~kW}$ Power Processor for the NSTAR Ion Propulsion Experiment," AIAA Paper 94-3305, 1994.
18. Sarmieinto, C.J., and Gruber, R.P., "Low Power Arcjet Thruster Pulse Ignition," NASA TM 100123, July, 1987. 19. Sarver-Verhey, T.R., and Hamley, J.A., "Discharge Ignition Behavior of the Space Station Plasma Contactor," AIAA Paper 94-3311, June, 1994.

20. Sarver-Verhey, T.R., " Continuing Life Test of a Xenon Hollow Cathode for a Space Station Plasma Contactor, “ AIAA Paper 94-3312, June, 1994.

Table 1. NSTAR PPU Power Supply Specifications

General Specifications

Output Ripple:

Load Regulation:

Line Regulation:

Outputs:

$\begin{array}{lccccc} & \text { Neutralizer } & \text { Discharge } & \text { Cathode Heaters } & \text { Beam } & \text { Accelerator } \\ \begin{array}{l}\text { Output } \\ \text { Voltage, V }\end{array} & 8-32 & 15-35 & 3-12 & 650-1100 & -(150-180) \\ \begin{array}{l}\text { Output } \\ \text { Current, A }\end{array} & 1-2 & 4-14 & 3.5-8.5 & 0.5-1.8 & 0-0.02 \\ \begin{array}{l}\text { Regulation } \\ \text { Mode }\end{array} & \begin{array}{l}\text { Constant } \\ \text { Current }\end{array} & \begin{array}{l}\text { Constant } \\ \text { Current }\end{array} & \begin{array}{l}\text { Constant } \\ \text { Current }\end{array} & \text { Constant } & 1 \text { surge } \\ \text { Voltage } & \text { Constant } \\ \text { Voltage }\end{array}$

$5 \%$ peak-to-peak of regulated output $\pm 5 \%$ of setpoint $\pm 5 \%$ of setpoint

Table 2. Sample NSTAR power throttling table

$\begin{array}{cccccccc}\begin{array}{l}\text { Beam } \\ \text { Volt., V* }\end{array} & \begin{array}{c}\text { Beam } \\ \text { Curr., A* }\end{array} & \begin{array}{c}\text { Accel. } \\ \text { Volt., V* }\end{array} & \begin{array}{l}\text { Dis. } \\ \text { Volt., V } * *\end{array} & \begin{array}{c}\text { Dis. } \\ \text { Curr., A ** }\end{array} & \begin{array}{c}\text { Neut. } \\ \text { Volt., V ** }\end{array} & \begin{array}{c}\text { Neut. } \\ \text { Curr., A* }\end{array} & \text { Power, W } \\ 1100 & 1.78 & 180 & 28.0 & 10.8 & 14 & 2 & 2288 \\ 1100 & 1.68 & 180 & 28.0 & 10.1 & 14 & 2 & 2159 \\ 1100 & 1.58 & 180 & 28.0 & 9.4 & 14 & 2 & 2029 \\ 1100 & 1.48 & 180 & 29.0 & 8.7 & 14 & 2 & 1908 \\ 1100 & 1.38 & 180 & 29.0 & 8.0 & 15 & 2 & 1780 \\ 1100 & 1.28 & 180 & 30.0 & 7.4 & 15 & 2 & 1660 \\ 1100 & 1.17 & 180 & 30.0 & 6.8 & 15 & 2 & 1521 \\ 1100 & 1.07 & 180 & 30.0 & 6.2 & 16 & 2 & 1395 \\ 1100 & 0.97 & 180 & 31.0 & 5.6 & 16 & 2 & 1133 \\ 1100 & 0.86 & 180 & 31.0 & 5.0 & 16 & 2 & 1011 \\ 1100 & 0.76 & 180 & 31.5 & 4.4 & 18 & 2 & 878 \\ 1100 & 0.64 & 180 & 32.0 & 4.2 & 20 & 2 & 744 \\ 1100 & 0.52 & 180 & 32.0 & 4.0 & 22 & 2 & 601 \\ 850 & 0.50 & 150 & 32.0 & 4.0 & 24 & 2 & 488 \\ 650 & 0.48 & 150 & 32.0 & 4.0 & 24 & & \end{array}$

* Power supply setpoints

** Resulting nominal value 


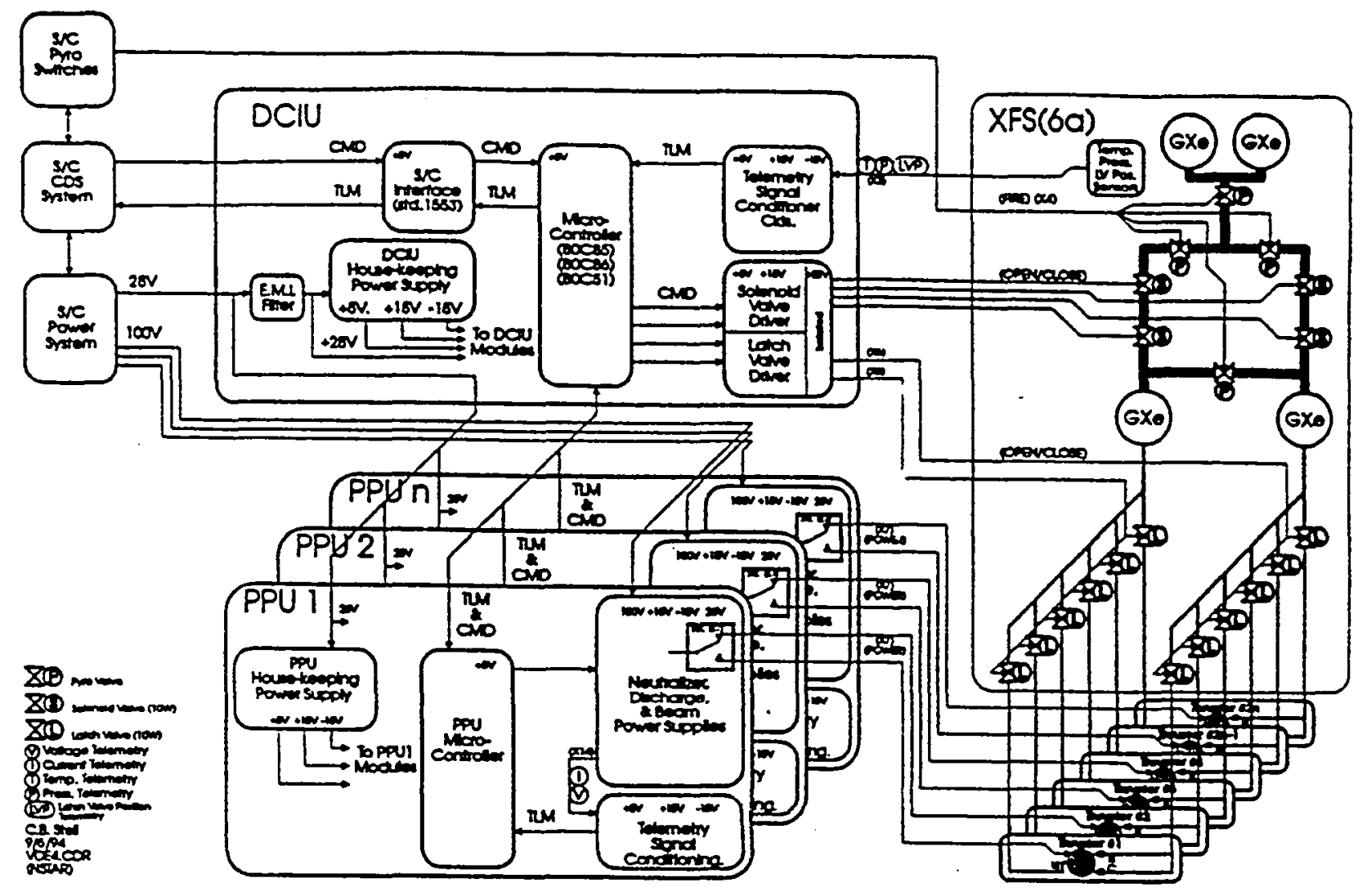

Figure 1. NSTAR system block diagram 


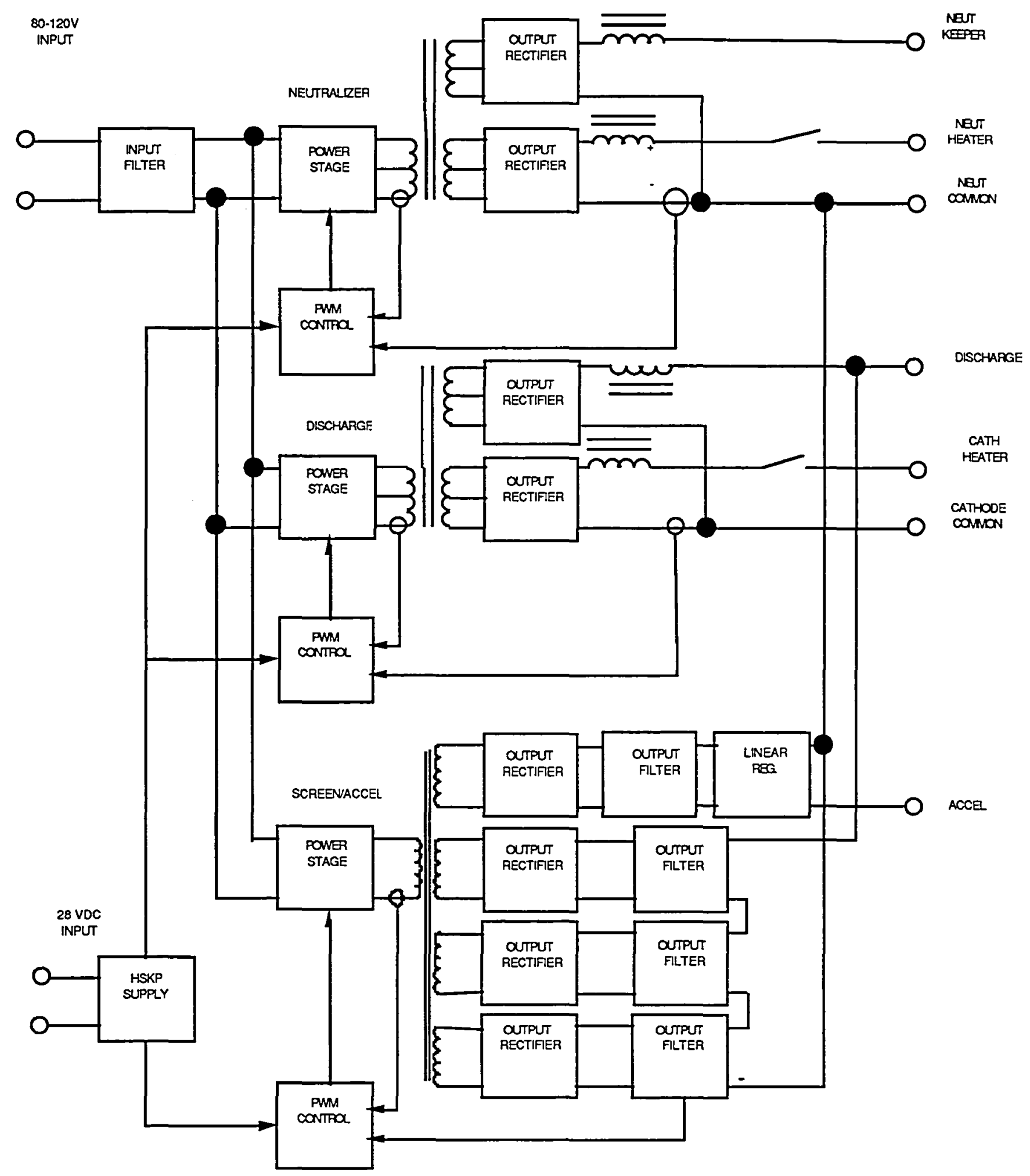

Figure 2. Block diagram of original NSTAR PPU design concept 


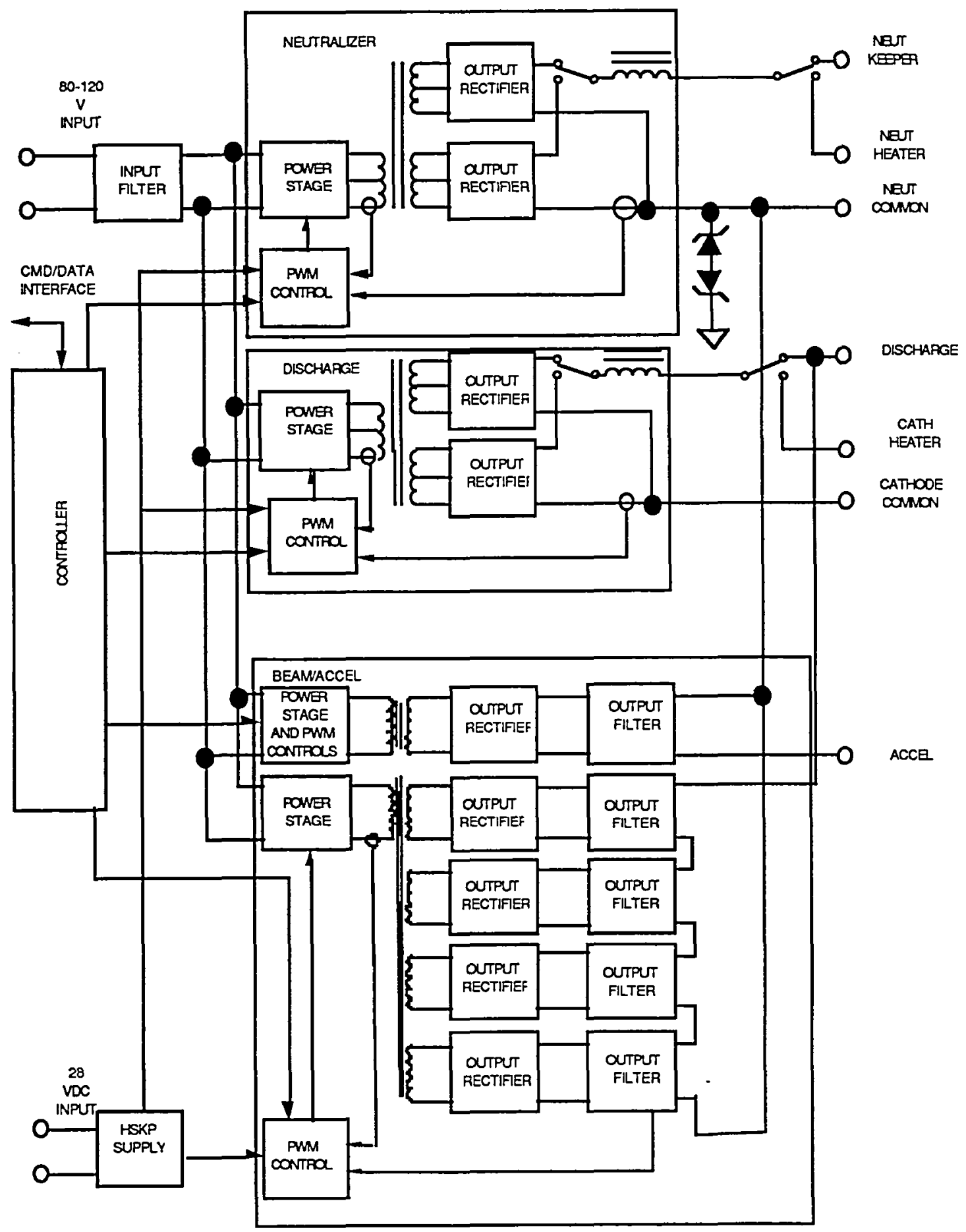

Figure 3. Block diagram of the present NSTAR PPU 


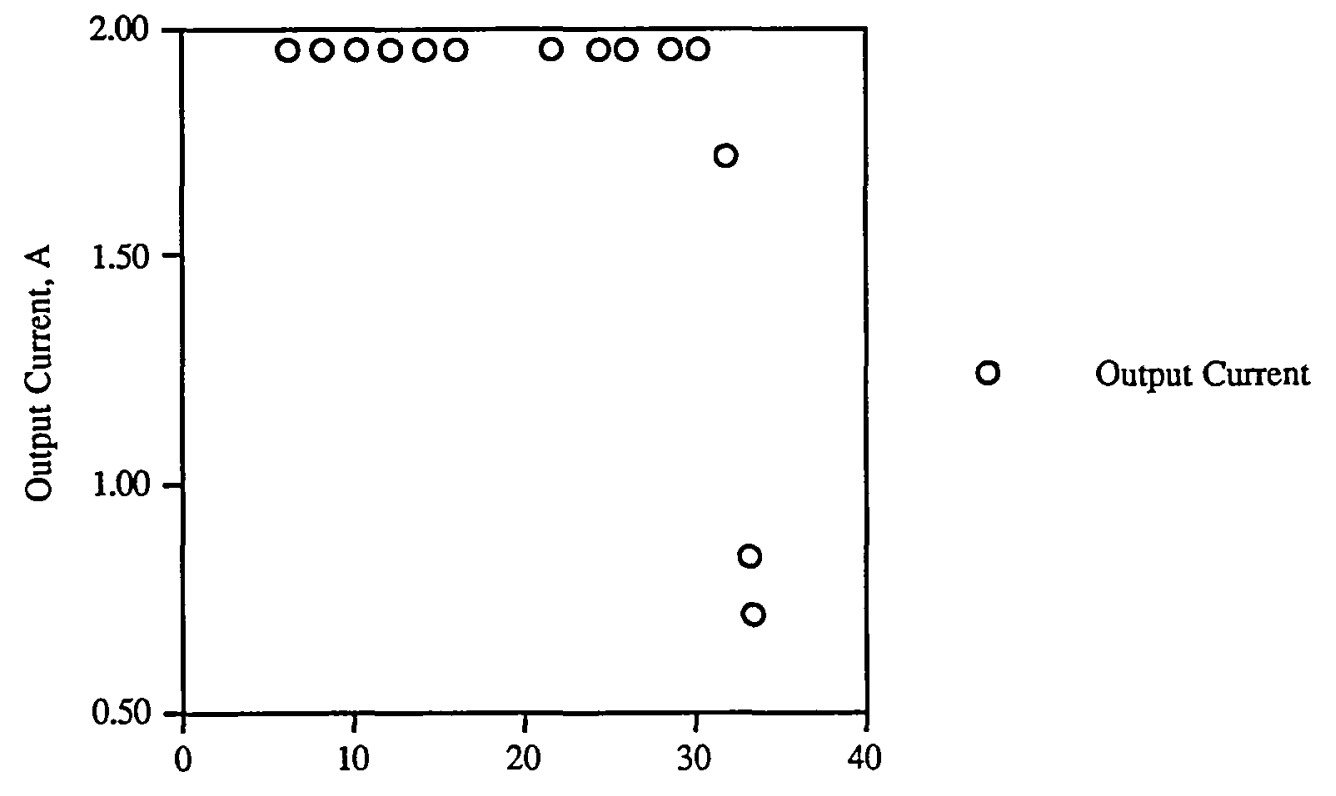

Output Voltage, $\mathrm{V}$

Figure 4. Results of Neutralizer load regulation tests

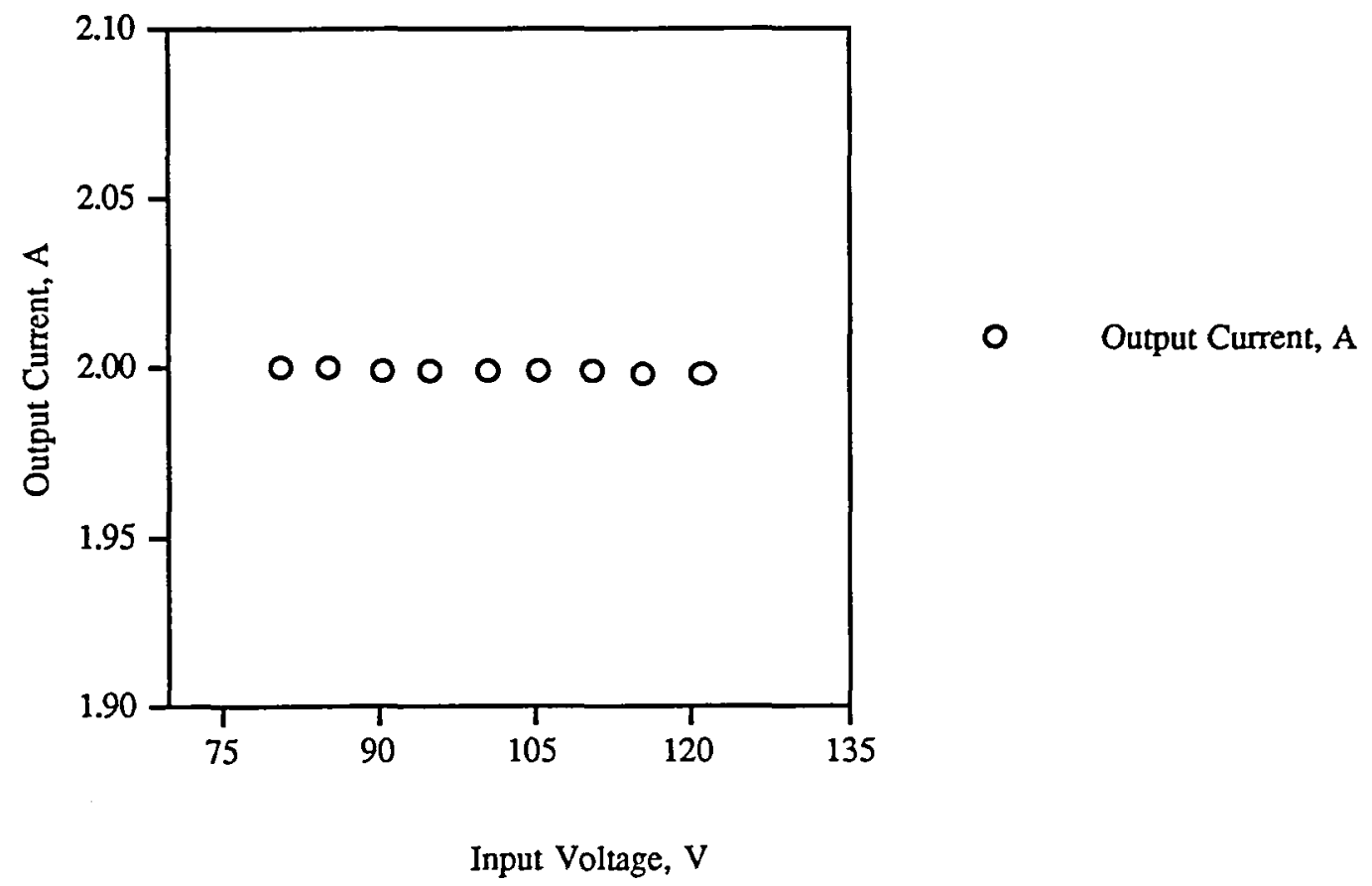

Figure 5. Results of neutralizer line regulation test 


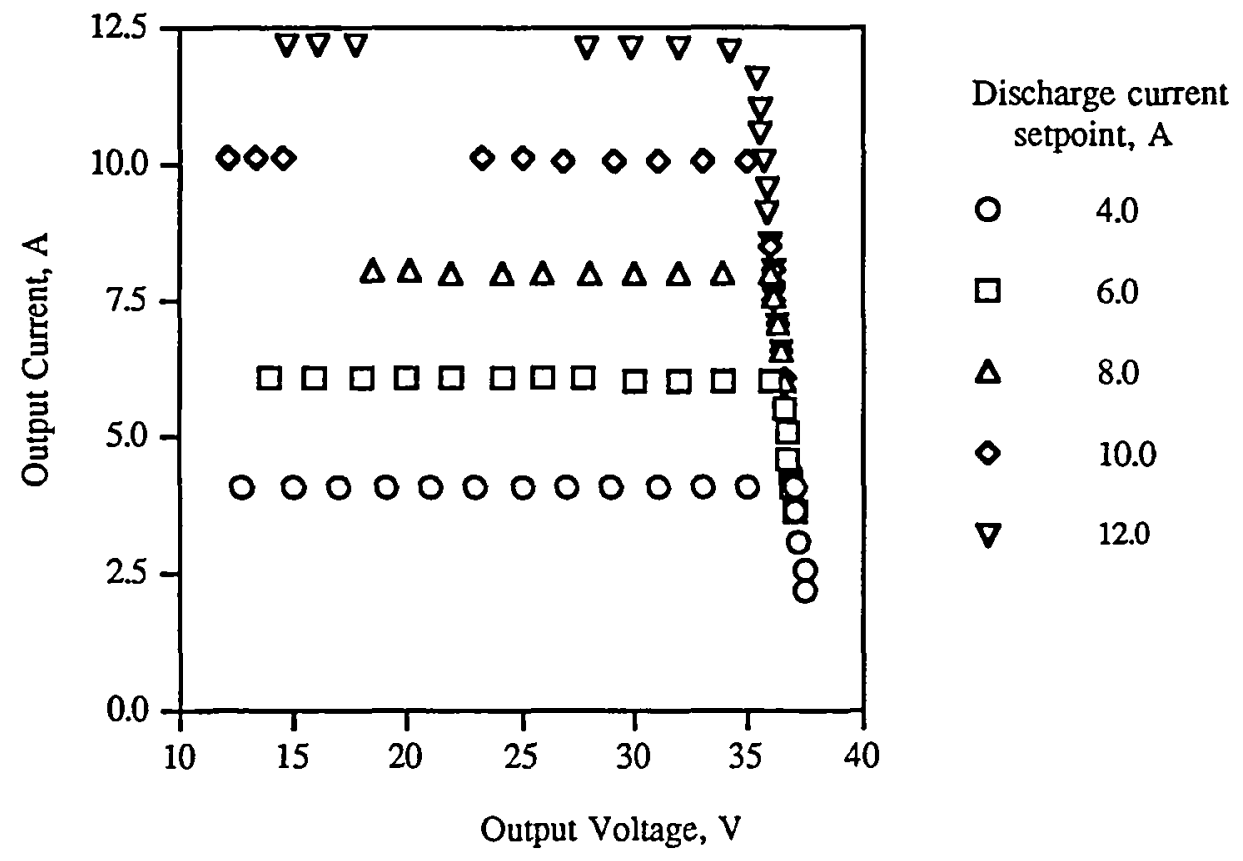

Figure 6. Results of discharge load regulation test

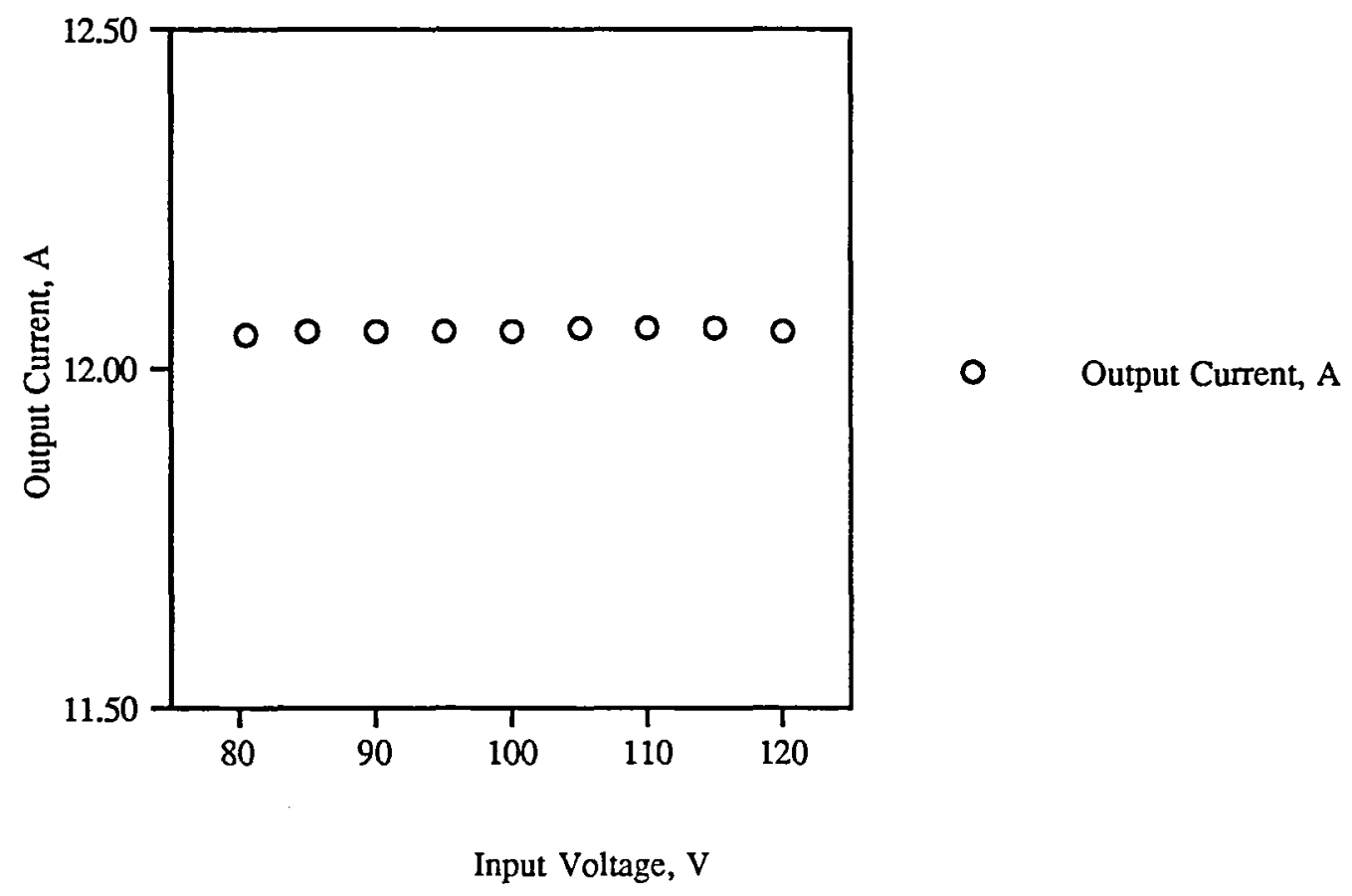

Figure 7. Results of discharge line regulation test 


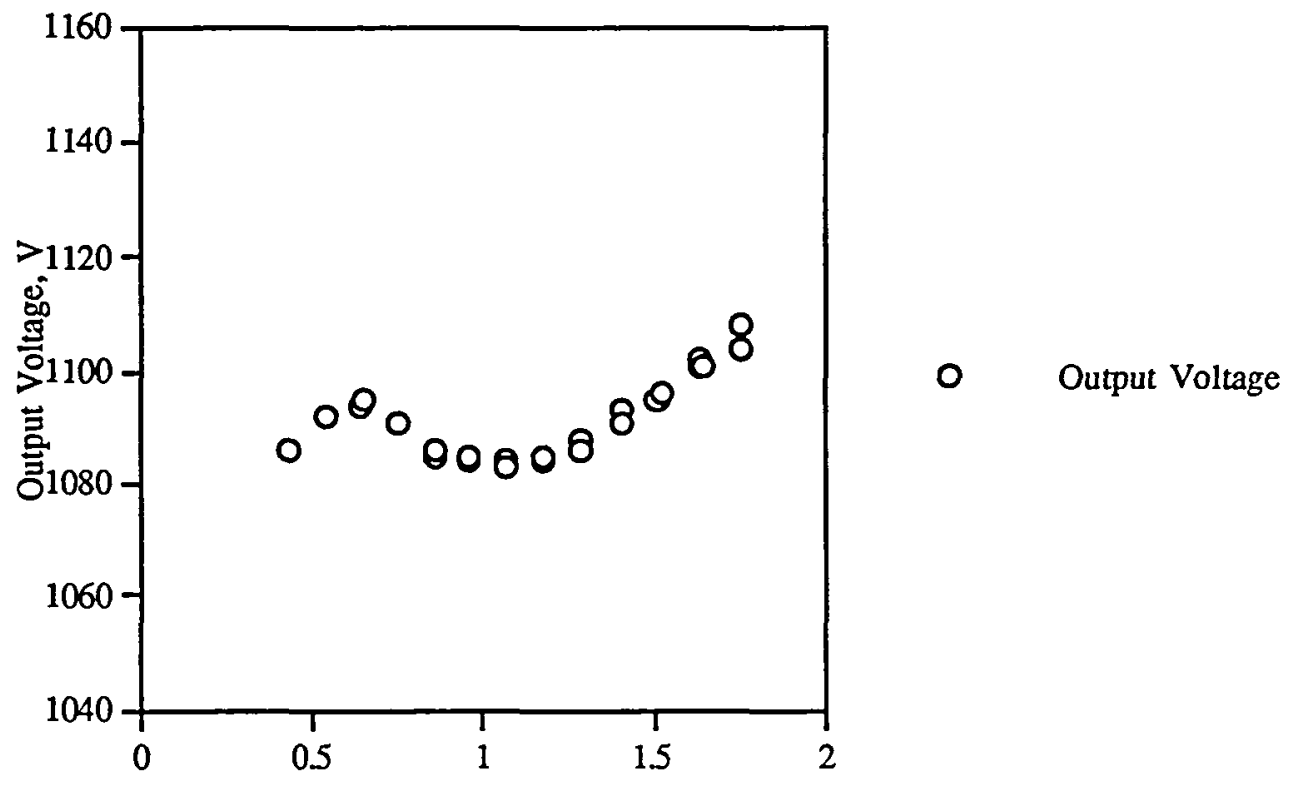

Output Current, A

Figure 8. Results of beam load regulation test

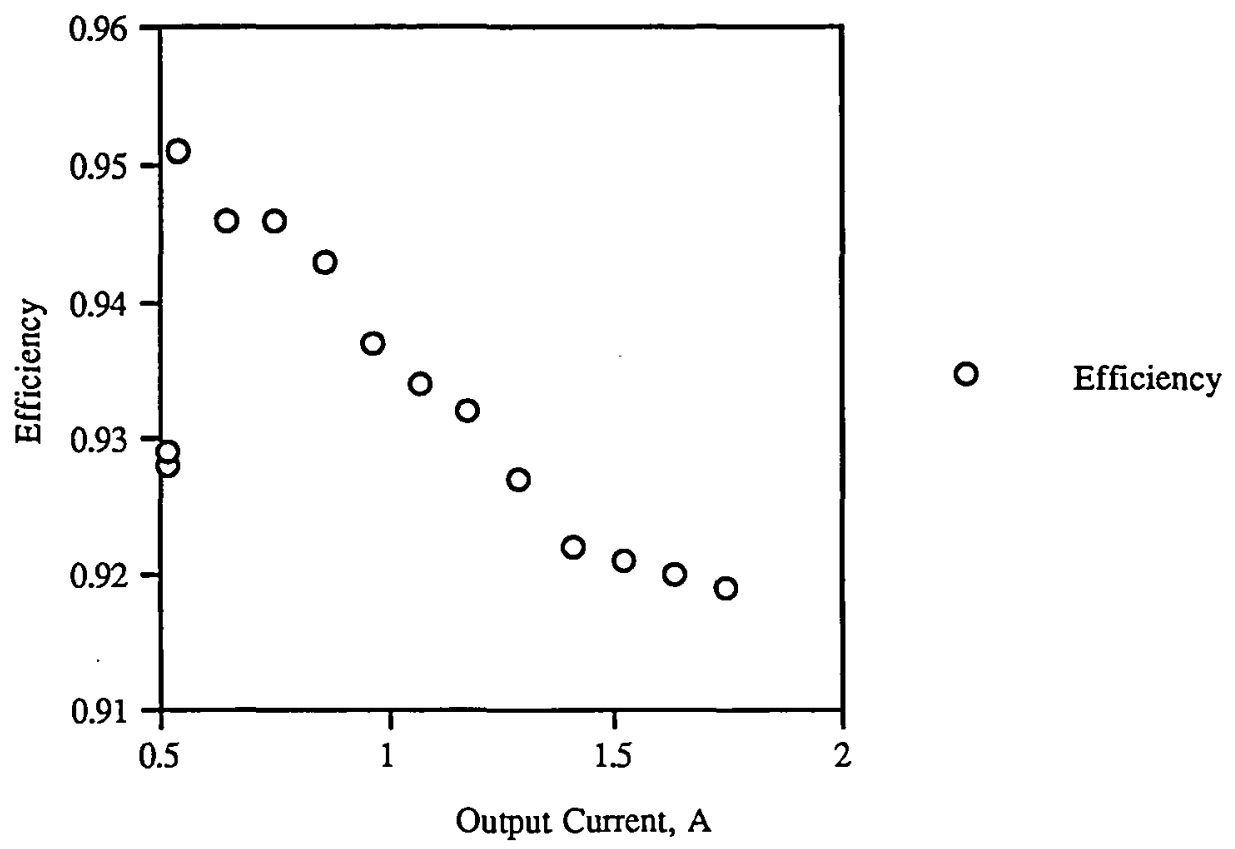

Figure 9. Beam power supply efficiency over full NSTAR throtling range 


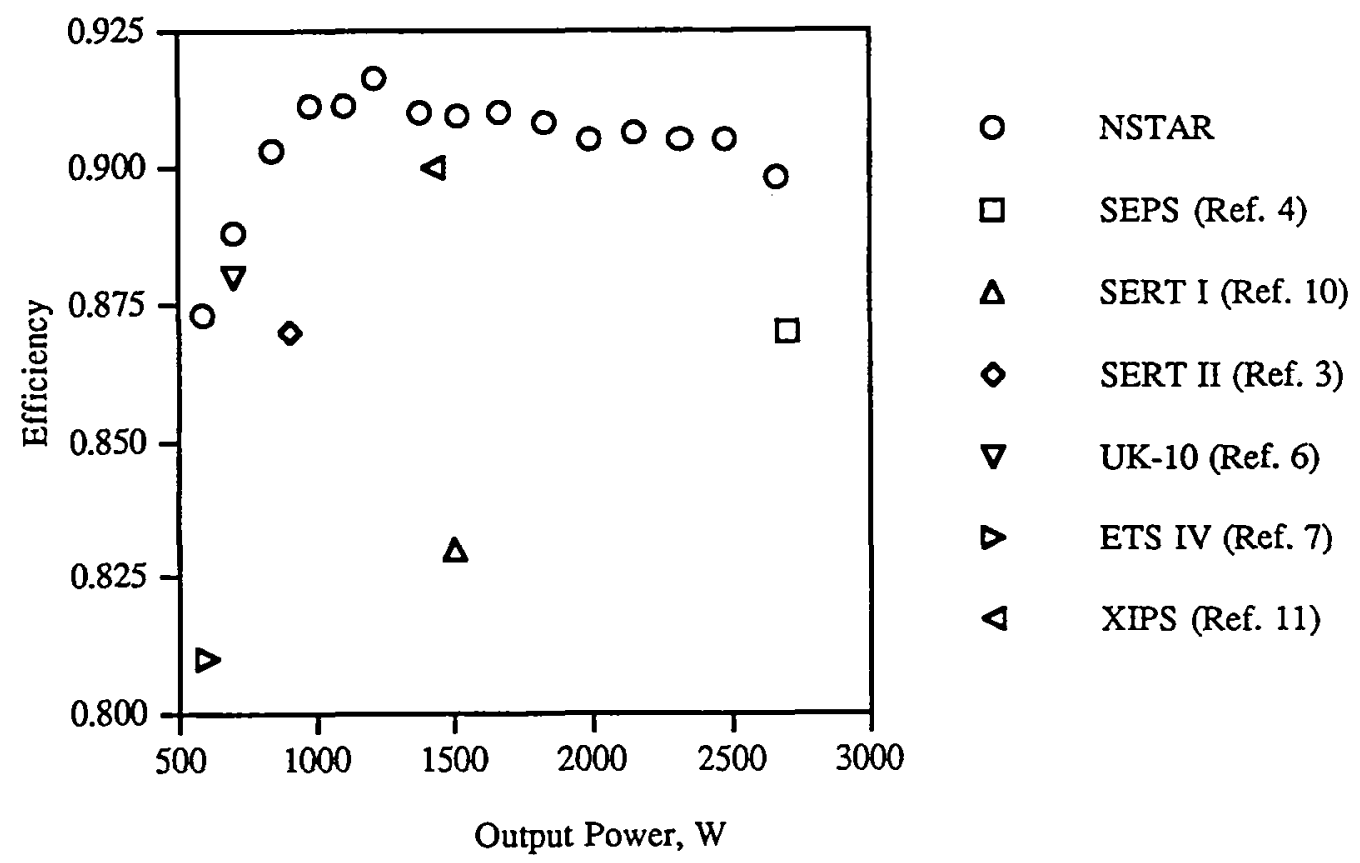

Figure 10. NSTAR PPU efficiency at various output powers compared to previous efforts in power processors for ion propulsion systems. The SEPS, SERT I, and SERT II utilized mercury propellant.

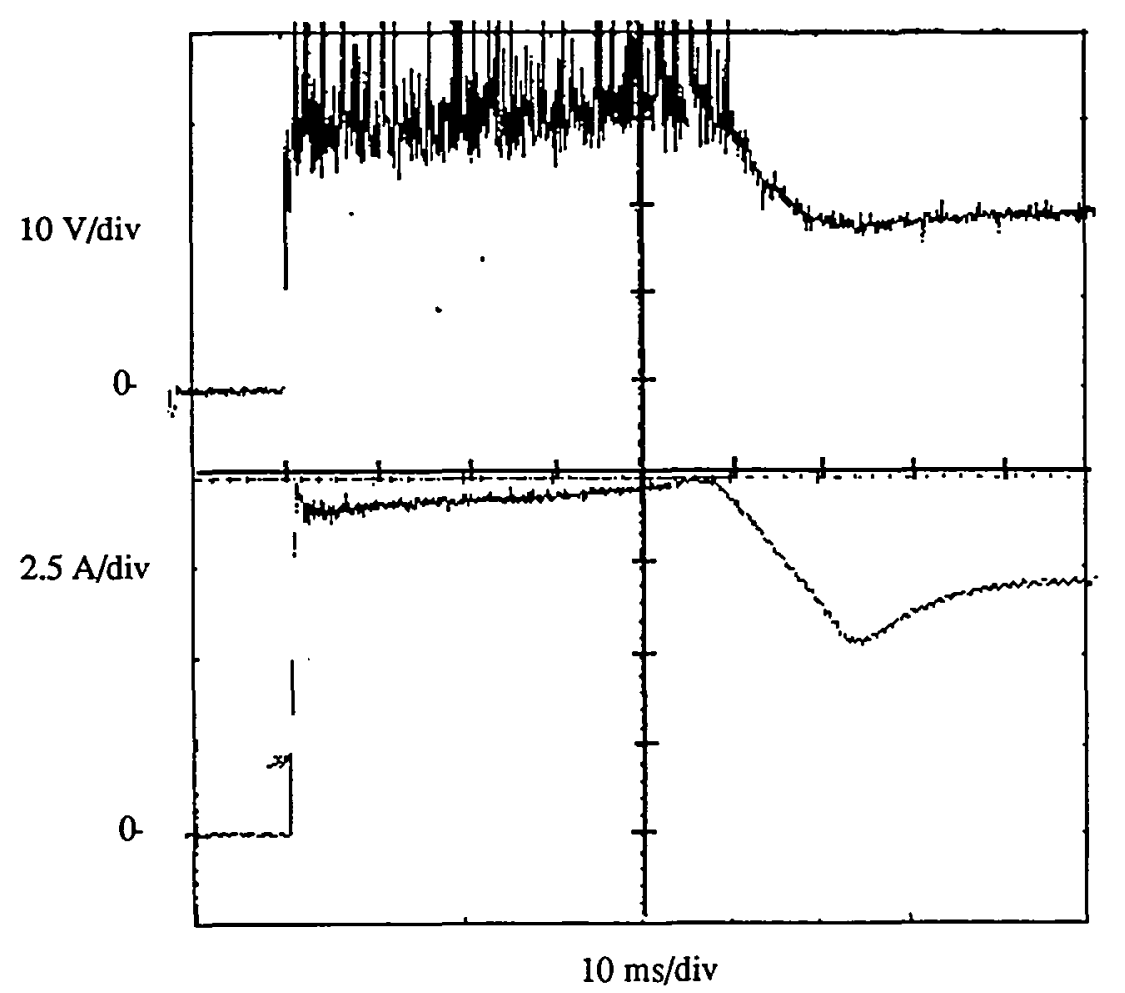

Figure 11. Discharge ignition on power supply open circuit voltage. Main flow rate: $18.6 \mathrm{sccm}$, Cath. flow rate: $2.9 \mathrm{sccm}$ 


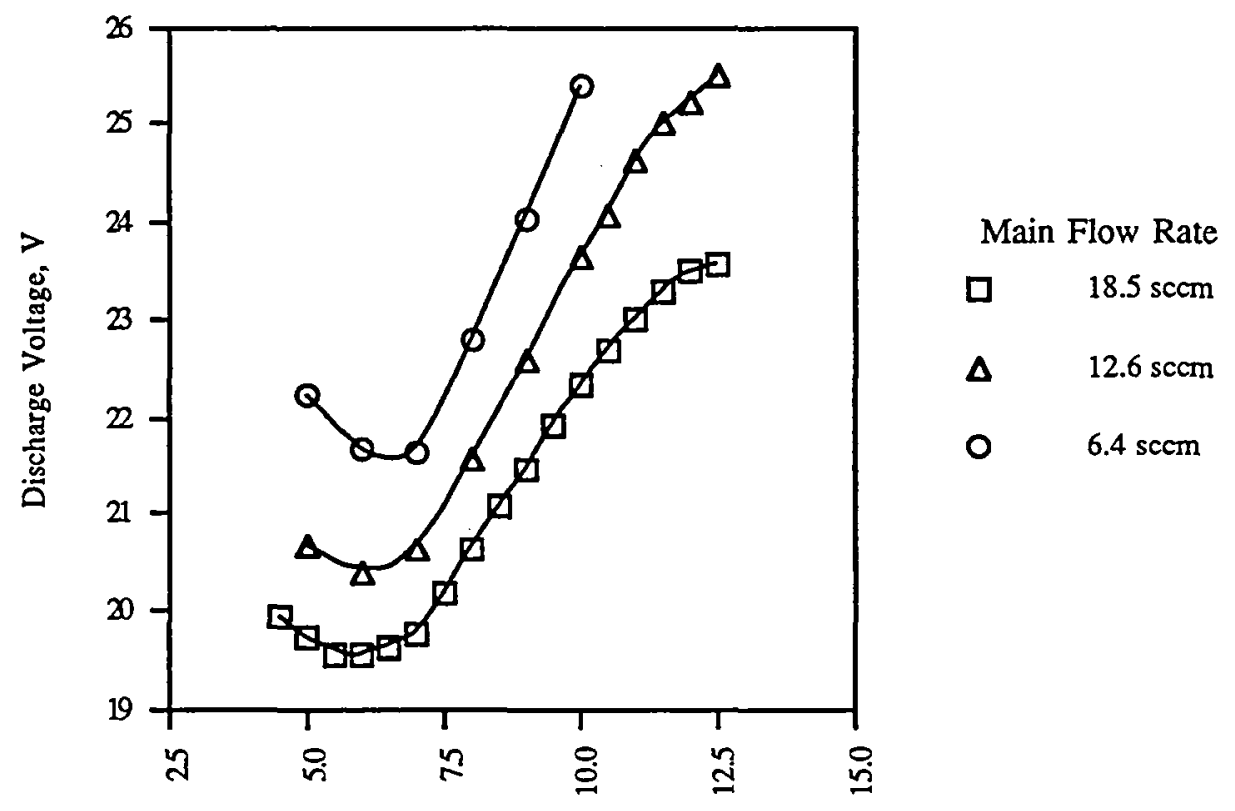

Discharge Current, A

Figure 12. Discharge volt-ampere characteristics at various main flow rates without beam extraction 
Public reporting burden tor this collection of information is estimated to average 1 hour per response, including the time for reviewing instructions, searching existing data sources. gathering and maintaining the data needed, and completing and reviowing the collection of information. Send comments regarding this burden estimate of any other aspect of this coliection of information, including suggestions for feducing this burden, to Washington Headquarters Services, Directorate for Intormation Operations and Reports. 1215 Jefterson Davis Highway, Suite 1204, Arlington, VA 22202-4302, and to the OHtice of Management and Budget. Papenwork Reduction Project (0704-0188), Washington, DC 20503.

\begin{tabular}{|l|l|l}
\hline 1. AGENCY USE ONLY (Leave blank) & 2. REPORT DATE & 3. REPORT TYPE AND DATES COVERED
\end{tabular}

\begin{tabular}{l|l|l|l} 
& October 1995 & Technical Memorandum
\end{tabular}

4. TIRE AND SUBTIRE

5. FUNDING NUMBERS

Development Status of the NSTAR Ion Propulsion System Power Processor

6. AUTHOR(S)

WU-242-70-01

John A. Hamley, Luis R. Pinero, Vincent K. Rawlin, John R. Miller, Kevin C. Cartier, and Glen E. Bowers

7. PERFORMING ORGANIZATION NAME(S) AND ADDRESS(ES)

National Aeronautics and Space Administration

Lewis Research Center

Cleveland, Ohio 44135-3191

8. PERFORMING ORGANIZATION REPORT NUMBER

E-9857

9. SPONSORING/MONITORING AGENCY NAME(S) AND ADDRESS(ES)

10. SPONSORINGMONITORING AGENCY REPORT NUMBER

National Aeronautics and Space Administration

Washington, D.C. 20546-0001

NASA TM-107037

AIAA-95-2517

11. SUPPLEMENTARY NOTES

Prepared for the 31 st Joint Propulsion Conference and Exhibition cosponsored by AIAA, ASME, SAE, and ASEE, San Diego,

California, July 10-12, 1995. John A. Hamley, Luis R. Pinero, Vincent K. Rawlin, and John R. Miller, NASA Lewis Research Center;

Kevin C. Cartier, Analex Corporation, 3001 Aerospace Parkway, Brook Park, Ohio 44142 (work funded by NASA Contract

NAS3-25776); Glen E. Bowers, Gilcrest Electric, Elyria, Ohio 44035. Responsible person, John A. Hamley, organization code 5330, (216) $977-7430$.

12a. DISTRIBUTHONAVAILABILITY STATEMENT

12b. DISTRIBUTION CODE

Unclassified - Unlimited

Subject Category 20

This publication is available from the NASA Center for Aerospace Information, (301) 621-0390.

13. ABSTRACT (Maximum 200 words)

A $0.5-2.3 \mathrm{~kW}$ xenon ion propulsion system is presently being developed under the NASA Solar Electric Propulsion Technology Application Readiness (NSTAR) program. This propulsion system includes a $30 \mathrm{~cm}$ diameter xenon ion thruster, a Digital Control Interface Unit, a xenon feed system, and a power processing unit (PPU). The PPU consists of the power supply assemblies which operate the thruster neutralizer, main discharge chamber, and ion optics. Also included are recycle logic and a digital microcontroller. The neutralizer and discharge power supplies employ a dual use configuration which combines the functions of two power supplies into one, significantly simplifying the PPU. Further simplification was realized by implementing a single thruster control loop which regulates the beam current via the discharge current. Continuous throttling is possible over a $0.5-2.3 \mathrm{~kW}$ output power range. All three power supplies have been fabricated and tested with resistive loads, and have been combined into a single breadboard unit with the recycle logic and microcontroller. All line and load regulation test results show the power supplies to be within the NSTAR flight PPU specification. The efficiency of the beam power supply, which processes $80 \%$ of the power in the PPU was 0.92 at the full specified power output of $1.98 \mathrm{~kW}$. The overall efficiency of the PPU, calculated as the combined efficiencies of the power supplies and controller, at $2.3 \mathrm{~kW}$ delivered to resistive loads was 0.90 . The component mass was $6.16 \mathrm{~kg}$. Integration testing of the neutralizer and discharge power supplies with a functional model thruster revealed no issues with discharge ignition or steady state operation.

14. SUBJECT TERMS

Electric propulsion; Ion thruster; Power electronics 15. NUMBER OF PAGES 17

\begin{tabular}{|c|c|}
\hline $\begin{array}{c}\text { 17. SECURTY CLASSIFICATION } \\
\text { OF REPORT } \\
\text { Unclassified }\end{array}$ & $\begin{array}{c}\text { 18. SECURTY CLASSIFICATION } \\
\text { OF THIS PAGE } \\
\text { Unclassified }\end{array}$ \\
\hline
\end{tabular}

\begin{tabular}{|c|c|}
\hline & $\begin{array}{l}\text { 15. NUMBER OF PAGES } \\
17\end{array}$ \\
\hline & $\begin{array}{r}\text { 16. PRICE CODE } \\
\text { A03 }\end{array}$ \\
\hline $\begin{array}{l}\text { 19. SECURITY CLASSIFICATION } \\
\text { OF ABSTRACT } \\
\text { Unclassified }\end{array}$ & 20. LIMITATION OF ABSTRACT \\
\hline
\end{tabular}


National Aeronautics and

Space Administration

Lewis Research Center

21000 Brookpark Rd.

Cleveland, $\mathrm{OH}$ 44135-3191

Olficial Business

Penalty for Private Use $\$ 300$

POSTMASTER: If Undeliverable - Do Not Return

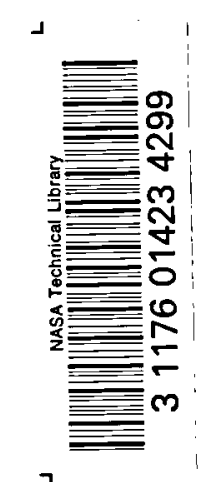

